\title{
Usage-Based Contact Linguistics: Effects of Frequency and Similarity in Language Contact
}

\author{
Nikolay Hakimov \\ Assistant Professor of Slavic Linguistics, Department of Slavic Studies, \\ University of Bamberg, Bamberg, Germany \\ nikolay.hakimov@uni-bamberg.de

\begin{abstract}
Ad Backus
Full Professor, Tilburg School of Humanities and Digital Sciences, Tilburg University, Tilburg, The Netherlands

a.m.backus@tilburguniversity.edu
\end{abstract}

\begin{abstract}
The influence of usage frequency, and particularly of linguistic similarity on human linguistic behavior and linguistic change in situations of language contact are well documented in contact linguistics literature. However, a theoretical framework capable of unifying the various explanations, which are usually couched in either structuralist, sociolinguistic, or psycholinguistic parlance, is still lacking. In this introductory article we argue that a usage-based approach to language organization and linguistic behavior suits this purpose well and that the study of language contact phenomena will benefit from the adoption of this theoretical perspective. The article sketches an outline of usage-based linguistics, proposes ways to analyze language contact phenomena in this framework, and summarizes the major findings of the individual contributions to the special issue, which not only demonstrate that contact phenomena are usefully studied from the usage-based perspective, but document that taking a usage-based approach reveals new aspects of old phenomena.
\end{abstract}

\section{Keywords}

contact-induced change - code-switching - language mixing - usage - frequency effects - linguistic similarity 


\section{Introduction}

Contact phenomena have been explained in many different ways: through social motivations, unintentional psycholinguistic mechanisms and aspects of structural compatibility. Roughly, these explanations align with sociolinguistic, psycholinguistic and linguistic perspectives on these phenomena. While obviously not without merits, these different perspectives generally do not share a common underlying view of linguistic knowledge and language use. The selling point of a usage-based approach is that it abandons a separate linguistic layer, reducing all language phenomena to a combination of the social and the cognitive determinant of verbal output (cf. Five Graces Group, 20o9). By explicitly relating function (or "meaning"), structure (or "form") and processing (or "use") to each other, a usage-based approach calls for and enables an integration of these diverse explanations (cf. Backus, 2015, 202O; Hakimov, 2017 , to appear). As a result, usage-based analyses will have to provide an alternative to purely structural analyses, and reframe structuralist explanations as deriving from social or cognitive considerations or, usually, both. The goal of the special issue is thus to demonstrate that language contact phenomena are usefully studied from a usage-based perspective.

Traditional contact linguistics has kept with the general way in which the field of linguistics and the study of language has been stratified. It hence describes contact phenomena as phonological, lexical, structural, and pragmatic. In contrast to this trend, a usage-based approach promotes a slightly different framework for data description because the traditional 'modules' of linguistic description are not recognized as always theoretically relevant. It hypothesizes that an individual's linguistic competence, or knowledge, is that person's inventory of meaning-form parings, referred to as units in Langacker's (1987) sense, and no unit can therefore be only phonological, morphological, syntactic or semantic. The concept of a unit goes back to the Saussurean notion of the linguistic sign, which combines a form and a meaning. Crucially, forms can be smaller, or larger, than a word and include morphemes, collocations, and fixed expressions. They may allow for inflection and contain or instantiate semantically or functionally specified open slots, for example in lexico-grammatical constructions, or grammatical templates. Meanings may range from specific grammatical functions (for grammatical formatives) to complex content (for expressions), and from referential meanings, as conveyed by words in the traditional sense, to pragmatic nuances, marked for example by word order patterns. Against the background of this conceptualization of competence, it becomes difficult to maintain a strict categorization of contact phenomena along the traditional lines of analysis. 
Beyond the need to develop usage-based contact linguistics and showcase its application to a variety of contact phenomena, this special issue aims at investigating aspects of language that have so far received scant attention in mainstream usage-based linguistics. For example, despite usage-based linguists' concern with processes of emergence and change (cf. MacWhinney and O'Grady, 2015), overt links to fields that put language change center stage, such as contact linguistics and sociolinguistics, are remarkably rare (cf. Backus, 2014). Another aspect of language use that is underexplored but pertinent to the emergence and development of an individual's linguistic knowledge is similarity between linguistic expressions and its detection in the process of language use (cf. Bybee, 2010). In contrast, contact linguistics relies on a long tradition of research engaged with issues of cross-linguistic similarity and equivalence, to account for why, where and under what circumstances languages influence each other (e.g., Weinreich, 1979 [1953]; Poplack, 1980; MyersScotton and Jake, 1995). Hence, analyses of contact phenomena, such as the articles in this special issue, can produce new insights into the role of similarity in the emergence, use and development of linguistic knowledge and thus contribute to usage-based theory-building.

This introductory article outlines a basic theoretical framework for the special issue and provides an overview of the seven original research articles included in the issue. It contains five sections. Section 1 introduces some of the key principles of usage-based linguistics, with a focus on exemplar-based approaches to language. Sections 2 and 3 address the role of frequency and similarity in language contact, respectively. Section 4 details our approach to contact phenomena along the lines of usage-based linguistics. Finally, Section 5 summarizes the principal findings reported in the individual contributions.

\section{Usage-based Approaches to Language}

In an overview of usage-based linguistics, Diessel (2017:6) states that this research strand has often been associated with the analysis of memory-related processes because its representatives have continuously emphasized the role of frequency in the emergence of linguistic knowledge. However, memory is only one domain that influences language users' linguistic behavior and the organization of language. According to Diessel, other domains include social cognition, encompassing phenomena such as joint attention, common ground and convention (cf. Croft, 2000: 87-99), and conceptualization, defined as the conceptual structuring of experience (Croft and Cruse, 2004:3). As the focus of the special issue is on the effects of frequency and similarity in language 
contact, memory-related processes such as storage and activation will take center stage in this introduction. However, we will also consider aspects of conceptualization, particularly when similarities in the conceptualizations underlying specific linguistic expressions of the languages in contact impact bilingual speech, or when linguistic expressions of the contact languages that are similar in form, or usage patterns, lead to conceptual transfer. We therefore restrict this introduction to a brief description of processes that pertain to the domains of memory and conceptualization and refer the readers to the Five Graces Group (2009) and Diessel (2017) for more comprehensive reviews.

A fundamental tenet of usage-based linguistics is that mental representations of language are internal representations of an individual's experience with language in the cognitive system and that these representations emerge and are updated in language interaction. To explain the relationship between the nature of linguistic mental representations and an individual's experience, some proponents of the usage-based approach to language have drawn on exemplar theory (Bybee, 2001, 2010; Abbott-Smith and Tomasello, 2006; Goldberg, 2006). Exemplar theory is a general cognitive model of categorization that was proposed by cognitive psychologists interested in modelling experience-based concept learning (Medin and Schaffer, 1978; Nosofsky, 1988). According to this theory, concepts are represented by a cluster of remembered instances with similar attributes. These representation structures, labelled as exemplars, provide the ground for the classification of new tokens of experience. In this model, new tokens of experience are compared with the existing exemplars on account of perceptual similarity, including physical resemblance as well as relational similarity. If a new token of experience is perceived as equivalent to an existing exemplar, it strengthens this exemplar, and if a new token is considered as differing from the existing exemplars in some way, it may fade away or, when reinforced, form the basis of a new exemplar.

Crucially, in exemplar-based theory, similarity is viewed as a highly context-dependent relation (Nosofsky, 1988, 2011). The context-dependent nature of similarity is due to the selective character of attention as people focus only on properties that are relevant in a specific context and do not attend to others. As emphasized by Goldberg (2006: 46), the brain stores a partial abstraction of an encounter rather than an entirely specified memory of what was encountered. In other words, only the properties of an exemplar that have been (unconsciously) noticed are more likely to be recorded.

The view of categorization as exemplar-based has important implications for usage-based models of language. Firstly, exemplar-based categorization draws on the knowledge of specific experiences, although it allows for a certain degree of abstraction. Secondly, categorization of experience is grounded in 
context-dependent similarity relations between the stored exemplars and the perceived instances of experience.

In linguistics, the exemplar approach has been adopted successfully for research in phonology (Johnson, 1997; Bybee, 2001; Pierrehumbert, 2001). Bybee (2006) and other usage-based linguists (Bod, 2006; Goldberg, 2006; Diessel, 2016) have argued that this approach may also yield fruitful insights into morphology and syntax because it reflects the view that grammatical knowledge involves detailed information about specific items as well as lexico-grammatical patterns.

A usage-based approach to language holds that phonologically specific symbolic structures represented in the language user's memory may include not only simple words, but also affixed and compound words, and even word sequences. There is a consensus among usage-based linguists that linguistic expressions, regardless of their complexity, accrue representational strength ${ }^{1}$ in a language user's lexicon/grammar if the frequencies with which they are encountered, or used, increase (Langacker, 1987: 59; Bybee and Scheibman, 1999: 581; Tomasello, 2003: 106-107; Bybee, 2007: 283; Arnon and Snider, 2010; Lieven, 2010; Blumental-Dramé, 2012: 68). However, it is still an open question whether high usage frequency leads to the emergence of autonomous representations that are activated and accessed directly, or whether it only facilitates speeded online computation (for a comprehensive discussion, see Divjak and Caldwell-Harris, 2015). At the same time, first-language acquisition studies recognize the possibility of independent representations for complex linguistic structures by providing extensive evidence that language acquisition begins with learning repetitive multi-word and multi-morphemic adult expressions as unanalyzed wholes (Tomasello, 1992; Lieven, Pine and Baldwin, 1997; Dabrowska, 2004; Bannard and Matthews, 2008; Lieven, Salomo and Tomasello, 20o9; Arnon and Clark, 2011). In other words, although usage-based linguists accept the importance of frequency for the emergence and organization of linguistic knowledge, its role has not been elucidated completely to date.

Another principle underlying the usage-based approach to linguistic structure and meaning is that representations of linguistic knowledge are organized in a network of relations (Bybee, 1985; Langacker, 1987; Goldberg, 1995; Croft, 20o1; Traugott and Trousdale, 2013). Since Kruszewski (1995 [1883]: 101), there has been overall agreement that words are associated with other words by

1 Other researchers, such as Langacker (1987), Croft (2001), Tomasello (2003), BlumenthalDramé (2012), Schmid (2017), refer to the representational strength of a linguistic expression as its "entrenchment". 
ties of similarity along the phonetic and the semantic dimensions. ${ }^{2}$ As argued by Bybee (1985), similarity relations among words give rise to the emergence of morphological relations. For example, the internal structure of the word revitalize is a result of its relations with other words having similar phonetic and semantic features, including vitalize, revitalization, vital, rearrange, and the like. In terms of a usage-based exemplar approach, storing exemplars of words and word sequences that are similar on one or several dimensions in close proximity to each other in a network allows the emergence of exemplar clusters, or categories.

A corollary of the network organization is that exemplar clusters develop association relations based on similarity and coactivation patterns. Association relations in the exemplar space underlie generalizations of various degrees of granularity over exemplar clusters corresponding to phonologically specific items of various lengths and complexity. In other words, the network organization of the exemplar space has as an effect the representation of abstract structure, including phonological, morphological and syntactic structure (Bybee, 2002; Vihman and Croft, 2007; Booij, 2010). Generalizations over exemplar clusters yield basic units of grammar, which usage-based approaches describe in terms of constructions. These units are defined as "direct form-meaning pairings that range from the very specific (words and idioms) to the more general (passive construction, ditransitive construction), and from very small units (words with affixes, walked) to clause-level and even discourse-level units" (Five Graces Group, 2009: 5; cf. Croft, 20o1; Goldberg, 2006). When language users perceive, or produce, same sequences of words differing only in some aspect, exemplar categories for both the invariable and the varying items emerge (Boas, 2003; Goldberg, Casenhiser and Sethuraman, 2004; Dąbrowska and Lieven, 2005; Bybee and Eddington, 2006). The exemplars corresponding to the invariable elements form the fixed slots in a construction, while the varying exemplars represent a schematic slot in a construction. For example, in the process of perceiving and comprehending word sequences such as Keep an emergency bag within reach. Always keep the essentials within reach. Keep a pair of scissors within reach. Don't keep your phone within reach at all time, the language user categorizes them according to their semantic and formal features. As a result of the categorization process, the fixed slot [keep _ within reach] with the meaning 'to keep something close, accessible' and the schematic slot

2 Lexical representations consisting of a set of phonetic exemplars and a set of semantic exemplars may also be associated with further perceptual memories, such as visual or other auditory memories, which may include socially meaningful information (Pierrehumbert, 2002: 116-117; Drager and Kirtley, 2016: 5). 
[_- $]_{\mathrm{NP}}$ for the entity in focus may emerge, with the schematic slot instantiated by the expressions an emergency bag, the essentials, a pair of scissors, and your phone. If the language user experiences further similar word sequences as in (1) and the like, she may develop a more schematic and more elaborate construction: [KEEP X within (ONE'S) (arm's/eye's) reach (of Y)].

(1) a. Keep young swimmer within arm's reach.

b. More than $90 \%$ of adults keep their smartphones within their arm's reach.

c. This design enables keeping all surfaces and appliances within arm's reach of the homemaker.

d. My parents always kept us kids within eye's reach.

At the same time, we cannot rule out the possibility that depending on her linguistic experience, the speaker does not generalize so far and represents several specific constructions based on the given schema (cf. Dąbrowska, 2008; 2014).

Usage-based linguists agree that abstract constructions as well as their specific and partially specific instantiations are represented in the mental lexicon/grammar in a structured way, being shaped by the cognitive process of categorization and co-activation patterns in exemplar networks (cf. Bybee, 2013; Diessel, 2016). The frequency with which a linguistic element, or a linguistic construction, is used correlates with its representational strength and ease of activation in the production process. That is, the higher the usage frequency of a linguistic structure - an element, or a construction - the stronger its representation, and the more likely its selection in production. In a situation of language contact, the selection of a linguistic structure may also be driven by the formal, semantic and distributional properties of the equivalent in the other language/variety, including usage frequency, similarity in form and the underlying conceptualization, interactional appropriateness as well as recency in discourse (also referred to as "priming"). Before tackling the factors frequency and similarity as determinants of the selection process in language contact settings, i.e., the focus of the present special issue, it is necessary to present some fundamental ideas underlying conceptualization.

Under the usage-based model, meaning is based on conceptualization (Langacker, 1991; Talmy, 2000). The view that meaning is conceptualization does not automatically imply that there is an absolute one-to-one relationship between conceptual structure and linguistic meaning. Depending on the concept, one-to-one and one-to-many correspondences have been reported 
(for a comprehensive review, see Speed, Vinson and Vigliocco, 2015). The usage-based approach goes beyond this issue by focusing on general cognitive processes affecting conceptual structure and specific construal operations. According to Croft and Cruse (2004: 46-69), these cognitive processes are (a) attention/salience, including selection, scope (dominion), scalar adjustment, and dynamic attention; (b) judgement/comparison, encompassing categorization (framing), metaphor, and figure/ground; (c) perspective/situatedness, involving viewpoint, deixis, and subjectivity/objectivity; (d) constitution/ gestalt, comprising structural schematization, force dynamics, and relationality. Earlier and slightly different approaches include Fillmore (1976), Talmy (1977, 2000), Lakoff and Johnson (1980), Langacker (1987; 2008).

Usage-based linguists argue that language users conceptualize experience in multiple ways, even the same situation may be viewed, or framed, variably. Every semantic frame, either lexical or grammatical, conveys a different conceptualization. For example, hold the steering wheel vs. grip the steering wheel evoke different conceptualizations of the intensity of the situation being described. Different conceptualizations also involve grammatical contrasts between almost synonymous, and often truth-functionally equivalent, expressions, for instance in (2).

(2) a. Tom is as tall as Mary.

b. Mary is as tall as Tom.

The expressions in (2) differ in the order of the subject and the comparative complement. By selecting different reference points for comparison, expressed by the subject, the experience is conceptualized in different ways.

As emphasized by Diessel (2017: 10), recurrent conceptualizations of the same or similar experiences give rise to semantic conventions. Competing conceptualizations play an important role in language change, particularly in the process of grammaticalization (cf. Heine, Claudi and Hünnemeyer, 1991), but contact-induced grammatical change may also result from competing conceptualizations attributable to the semantic conventions of the contact languages.

Usage Frequency in Language Contact

Two veins of research in language contact have integrated frequency into their analyses so far: the typological study of borrowability and the study of bilingual speech within the framework of variationist sociolinguistics. In the former 
approach, category borrowability is linked to the number of borrowed items representing this category in a corpus (cf. Matras, 2013: 77-78). The frequencies of borrowed items by structural category provide the basis for establishing scales, or hierarchies, of borrowability, such as the hierarchies proposed by Haugen (1950: 224), or Muysken (1981). Work in variationist sociolinguistics has utilized the token frequency of a (lexical) item from a contact language as an indicator of its status as an established borrowing (Popack, Sankoff, and Miller, 1988; Sankoff, Poplack, and Vanniarajan, 199o; see also Myers-Scotton, 1993: 191-207), and has analyzed the cumulative recurrence rates of borrowing as indices of the diachronic lexical development in contact varieties (Poplack and Dion, 2012). However, these accounts of borrowability and approaches to loanword development seek explanations in structural and social factors, instead of conferring explanatory value on usage frequency perse. In contrast to these research strands, usage-based approaches to language contact seek explanations in distributional factors, which reflect both processing biases and socio-interactional conditions of language use, and relate the frequency of an individual linguistic structure to the selection potential thereof in bilingual production, while not ignoring social motivations for the selection process (cf. Backus, 2014: 23-28).

Earlier analyses of bilingual speech within the framework of cognitive linguistics, such as Backus (1996, 2003), have argued that the usage frequency of a linguistic unit influences its selection in bilingual speech. Analyzing a corpus of Dutch-Turkish bilingual speech, Backus (2003: 104) observes that at least half of the Dutch compound nouns occurring in otherwise Turkish sentences are high-frequency items. In a similar vein, Boumans' (1998: 386-387) attributes the insertion of adjective-noun combinations into otherwise MoroccanArabic sentences to the frequency with which the respective adjectives and nouns are used together in Dutch. He also ascribes the rarity of modification of Dutch nouns by Moroccan-Arabic adjectives to the absence of collocational ties between the involved lexical items. More recently, Hakimov (2016a, 2016b) has presented positive evidence that usage frequency predicts, among other factors, the insertion of inflected words as well as multiword sequences in bilingual sentences. However, the role of frequency and particularly its interaction with other factors, including priming in discourse and structural similarity between the contact languages, are not yet fully understood.

The issue of cross-linguistic similarity has been a focus of scholarly attention from the very beginnings of contact linguistics. Describing mechanisms 
and structural motivations of linguistic interference, Weinreich (1979 [1953]) observes that bilingual individuals identify the basic units and patterns of one of their languages and map them on the units and patterns of their other language. This process, labeled as "interlingual identification of expression and content units", is regarded as part of bilingual experience itself. Weinreich argues that interlingual identification of forms and meanings in bilinguals is ongoing and shows that even when some expression and content units in the bilingual individual's languages may be incompatible, certain overlappings may still be identified (ibid.: 8). Höder (2012) offers a current articulation of this approach along the lines of construction grammar. Similarly, researchers studying codeswitching have frequently drawn on structural similarity, also referred to as "equivalence" (Poplack, 1980), or "congruence" (Myers-Scotton and Jake, 1995), to account for the structure and variability of bilingual speech. As shown by Sebba (2009), similarity between language-specific structures of contact languages opens up possibilities for codeswitching and thus contribute to the emergence of grammatical patterns in bilingual speech.

Under the usage-based model, as outlined in section 1, grammar is viewed as "the cognitive organization of one's experience with language" (Bybee, 2006: 711). This organization is grounded in the brain's capacity to perceive and categorize new information as identical, similar or different to what is already stored. Therefore, every event of using language involves a process of comparing, and one of updating one's linguistic knowledge with the newly experienced or produced instance of language use. These processes shape and affect the linguistic knowledge of speakers, including bi- or multilingual ones, for whom categorization and activation of memory traces may affect the representations of both languages, even at events when only one of their languages is used (cf. Gampe, Endesfelder Quick and Daum, this issue).

As an individual's experience with language is unique, no matter whether it is monolingual or multilingual, similarity evaluation, including interlingual identification, is an arbitrary and highly subjective process. Experience-based categorization brings about idiolectal variation, in both language use and the internal organization of linguistic representations (Dąbrowska, 1997). This view of similarity identification and categorization contrasts sharply with structuralist approaches, which ascribe the outcomes of language contact to the typological parallels between the contact languages, as documented in linguistic descriptions of these languages. However, more and more evidence has become available in favor of the usage-based position (cf. Verschik, 2019). For example, by utilizing a sample of genetically unrelated and/or typologically distinct minority languages in contact with Russian in the Russian Federation, Forker (2020) shows that no unambiguous relation exists between genetic 
relatedness, or typological similarity, on the one hand, and the patterns of borrowing from Russian, on the other hand. Research work in the vein of usagebased linguistics such as Babel and Pfänder (2014: 254) argues that "typology is not the defining factor of language convergence or divergence; rather, speakers' perceptions of differences and similarities are crucial to their development and change". Bullock, Serigos and Toribio (this issue) emphasize that specific innovations in the Spanish varieties of Texas are attributable to the local socio-interactional conditions of contact. Crucially, despite the high number of Spanish-speaking communities across the United States, most of which are bilingual, the reported contact-induced innovation is characteristic of the Spanish-speaking communities in the south-west of the United States and particularly of certain communities in Texas. In sum, a usage-based approach holds that a bilingual individual engages in similarity detection (and even construction) in usage events, or contextualized encounters, and that depending on the context, the similarities perceived by that individual may overlap with or differ from the similarities perceived by another bilingual individual, even in the same communicative situation.

Speaking is always a balancing act between reusing memorized (and usually conventionalized) units and choosing the best way to construe and verbalize the currently needed information, which is by definition unique and novel, but at the same time similar to previously perceived information (cf. Croft, 2000). Following this thought, we can reverse engineer observable linguistic data to see how during concrete usage events bilinguals may produce utterances that instantiate the early manifestations of cross-linguistic influence.

\section{5 Contact Phenomena from the Usage-based Perspective}

Whenever an example of contact-induced change is observed, some kind of comparison between the languages has to be made in order to account for the change. The paradigm case is that of borrowing, when an element originating in Language $\mathrm{B}$ is added to Language $\mathrm{A}$, or that of semantic and distributional change, when something in Language A has changed in the way it is used. In the first case, speakers introducing the new element must have felt, consciously or unconsciously, that Language A lacked the element from the other language that they wanted to use. In the second case, evaluation of similarity between the desired element from Language $\mathrm{B}$ and one, or more, of its equivalents in Language A has had the result that the overlap between them was not judged high enough to warrant the continued use of the Language A equivalent and led to the alteration in the usage of this equivalent. An important 
task for usage-based contact linguistics is to describe this process of similarity checking in cognitively plausible terms, rather than in merely structuralist ones, preferably in an account from which testable hypotheses can be derived.

The question now is whether this usage-based account of language use and the dynamic build-up of linguistic knowledge in the mind can also inject new insights into the main issues in contact linguistics, such as the ones addressed by the various articles in this issue. At the most abstract level, the main issue may be summarized as why some words and constructions tend to be used in bilingual speech and may undergo regularization and conventionalization and others not.

With words and other lexical units, it has been observed that foreign words stand the best chance of becoming selected if they have relatively specific meaning, while words with general meaning tend to be from the base language (Backus, 2001; Hakimov, this issue). This suggests that if intended meaning is clearly represented in an already entrenched unit of the base language, activation and selection of any equivalent in the other language is not likely. It is not entirely clear why this is, but one logical possibility is that general words are often part of larger multiword units and partially schematic constructions: their selection is a by-product of the selection of the larger unit. The activation of an other-language unit is easiest if its meaning is not shared by anything in the receiving language, that is, if this unit fills a "lexical gap", loosely defined. Assuming that the bilingual speaker considers that meaning most appropriate in a specific communicative context, the other-language unit is then the only candidate for selection. It will only be suppressed if codeswitching is not appreciated in the current communicative context. In that case, some near-synonym from the base language may become selected or the meaning will be circumscribed in some other way, or the foreign word is used anyway but accompanied with discourse flagging.

By the same logic, a grammatical construction from Language $B$ should not be easily activated while Language $A$ is being spoken except for the rare occasions where it fills a structural gap. However, interference and structural borrowing may occur not only as a result of structural gaps; so there must be some mechanism that leads to the activation of a grammatical construction from B. The key, we suggest, lies in the combination of high frequency and similarity in form across the languages. If the form of a frequently used construction in Language B, such as the svo word order for conveying pragmatically neutral content, is judged as similar to the form of a superficially equivalent construction in Language A, say svo word order for information that is not pragmatically neutral but in which the object argument is pragmatically backgrounded, its use may trigger further reinforcement of the Language A construction's 
representational strength, even if the morphological and lexical slot fillers are from Language B. However, this produces a clash between two different meanings for the same construction, where in an actual synchronic instance of use it can only have one: pragmatically neutral or backgrounding of the object, in our example. Since for bilingual speakers the neutral meaning is reinforced much more often than the more specialized one, this meaning may slowly but surely take over in the mental representation for what becomes a single unit: svo with neutral pragmatic meaning. The result is increased use and semantic change of the construction, under "foreign" influence.

This suggests an interesting contrast between the roles of similarity and difference. When a lexical unit is noticed in Language $B$ that is markedly different from a close equivalent in Language A, it may be used in Language A when needed, surfacing as a codeswitch. Here it is the lack of complete similarity that does the trick. However, when a grammatical pattern in Language B is similar to a pattern in Language $A$, it may reinforce the use of the pattern in Language A, and here we assume it is the similarity that caused the change. Perhaps there is a trade-off between specific meaning, which causes the mind to notice subtle differences, and general meaning, which causes the mind to ignore subtle differences. The communicative motivations behind the principle could be that specific meaning needs cognitive attention because of its importance in conveying the adequate meaning, while general meaning is backgrounded: the mind should be trusted to activate the same old units it always activates, to avoid cognitively costly prediction error, which would, in turn, keep the mind from focusing on the specific content encoded by content words, multiword units and some partially schematic constructions.

Corpus data ultimately will only give us circumstantial evidence for such scenarios. It will be a challenge, however, to design experimental studies that can test these claims while not destroying ecological validity to a problematic extent.

The different topics addressed by the contributions to this special issue roughly converge in two thematic clusters: the role of detected similarity, either perceived or assumed, in bilingual language acquisition and language change, and the impact of recurrent (partially) specific units on the structure of bilingual speech. At the same time, all of the contributions explore the potential of the usage-based approach to account for a range of language contact phenomena, including codeswitching and contact-induced grammatical change. 
The articles in the special issue take as a starting point the fact that high usage frequency imparts a lower selection threshold to mental representations of linguistic structures. In situations of bilingualism, particularly the structures of the more frequently used language, which is often the socially dominant one, may be more available to bilinguals than similar structures of the other language. Specifically, a lot of variation in bilingual speech, as the contributions by Goria, Hakimov and Lantto show, is due to the abundance of frequent word sequences (Goria; Hakimov) and the use of recurrent partially specific constructions (Lantto), both of which are easily activated. Even when bilinguals communicate in the monolingual mode while trying to suppress one of their languages, they yet have access to representations of other-language words and constructions of high frequency. The data and arguments presented in the contributions by Bullock, Serigos and Toribio, Rottet and Estigarribia provide support for the view that highly recurrent constructions of the unintended, but socially dominant language may be transferred to the language of interaction as loan translations in the first two cases, or as bilingual constructions in Estigarribia's case. According to these authors, the prerequisite for constructional transfer is subjectively established similarity in the form and function of linguistic constructions; in the case of Estigarribia's findings formal similarity is found to be lacking, triggering the use of source language morphemes. As reported by Gampe, Endesfelder Quick and Daum, similarity, like frequency, enhances representational strength of words and linguistic constructions and hence contributes to their availability to bilingual language users. Crucially, the nontrivial relationship between subjective similarity and usage frequency is still underexplored and is in need of further research.

The individual papers in this special issue are arranged into three sections: lexical (co-)activation and selection (Gampe, Endesfelder Quick and Daum; Hakimov; Goria), lexico-grammatical transfer owing to a considerable degree of similarity in form and meaning between the constructions in two languages (Rottet; Bullock, Serigos and Toribio), grammatical transfer in a situation when a formal overlap between the constructions in two languages is lacking or reduced (Lantto; Estigarribia).

Gampe, Endesfelder Quick and Daum's contribution presents an original study of the role of language similarity in bilingual children's lexical development. The article draws on different types of data, including parental reports of the bilingual toddler's lexical skills and computed similarity scores of the toddler's languages at the lexico-phonological and the morphosyntactic level. The results indicate that language similarity positively affects vocabulary acquisition in bilingual toddlers. The facilitatory effect of language similarity on the vocabulary acquisition rate is stable and reported for each of 
the bilingual's languages. The authors interpret these results in light of the usage-based exemplar theory, according to which representations of similar words, including bilingual cognates, are stored in close proximity to each other and may be subject to co-activation processes. More specifically, the authors argue that activation of a bilingual cognate in the bilingual lexicon may co-activate the respective other-language cognate's representation, strengthening it and facilitating memorization of both members of the bilingual cognate pair.

By way of a case study, Hakimov investigates the role of the factor "usage frequency" in selection processes that manifest themselves in bilingual speech production. The article analyzes a bilingual Russian-German corpus of naturally occurring conversations and informal group interviews to examine variation in switch-placement in one of the frequently reported loci of code-switching, namely, the adjective-modified noun phrase. In this corpus, German noun insertions in otherwise Russian sentences are modified by either Russian or German adjectives, hence resulting in mixed Russian-German constituents or German adjective-noun insertions. Frequency data was obtained for the respective adjective-noun combinations and their parts from a large German corpus and subjected, together with the dependent variable "switch placement", to statistical analysis. The latter analysis revealed two frequency effects: switch placement in the examined context is affected by the frequency with which adjectives and nouns are used together in German as well as by the frequency of the adjective; that is, while high-frequency adjectives come from the matrix language, here Russian, most adjectives in the mid- and the low-frequency band are realized in German. These findings are interpreted in terms of Backus' (2003) unit hypothesis and his (1996) specificity continuum, respectively. On the whole, the contribution yields support for the relevance of lexical specificity and the collocational ties between words to the structure of bilingual speech.

Goria's contribution presents an analysis of clause-peripheral codeswitching involving the left-dislocation and the pseudo-cleft construction. While previous analyses of clause-peripheral codeswitching have tended to assume a rather abstract level of these constructions (e.g., Muysken, 2000: 100-101; Treffers-Daller, 1994), this article shows that an overwhelming bulk of the left dislocations and pseudo-clefts in the author's corpus of English-Spanish bilingual conversations recorded in Gibraltar are highly repetitive, lexically specific instances of these constructions. By acknowledging the lexicalized status of the observed constructions, the author provides strong support for the view that switched multi-word fragments are frequently combined with the other-language clause because they are lexical chunks that are processed as 
single lexical items (cf. Backus, 2003; Hakimov, this issue). Hence, the contribution sheds light not only on the underpinnings of clause-peripheral codeswitching, but also on the general relevance of lexical chunks to speech production.

In his contribution, Rottet explores the transfer of directional verb-particle constructions from English to Welsh, a language heavily influenced by English due to long-standing bilingualism. The article focuses on the highly polysemous English construction [VP up] and its Welsh equivalent [VP $i$ fyny] and contrasts their metaphorical extensions as observed in a corpus of original Welsh texts. According to Rottet, the formal and functional similarity between the English and the Welsh directional non-idiomatic constructions favored their diffusion in Welsh. He provides evidence that the reported cases of metaphorical extension are clear examples of conceptual transfer because modern Welsh has not transferred English idiomatic combinations in a random fashion, but has done so in a rather systematic way. The conducted analyses and the provided historical evidence allow the author to propose a scenario for the emergence of Welsh directional idioms under English influence, in which a significant role is assigned to subjective similarity and Welsh speakers' growing amount of exposure to English.

Bullock, Serigos and Toribio examine a partially specific Spanish construction [agarrar NP], which is used to mean 'to get something' in Spanish varieties of Texas. By combining variationist and corpus-linguistic methodologies to analyze this construction in the bilingual Spanish in Texas corpus as well as in monolingual Spanish corpora they show that the innovative use of the verb agarrar 'grab, grasp' in this construction in Texas is modelled on the English support verb construction [get NP], as in get help. They report that in spite of comparable overall frequencies of agarrar in the Mexico and the Texas corpus, the verb exhibits differences in its collocational profiles and meaning. The semantic and distributional change of the agarrar NP construction in the Spanish of Texas may thus be regarded as a bona fide example of contact-induced conceptual transfer facilitated by the perceived structural similarity of the involved constructions and resulting in a grammatical innovation, namely the emergence of the English-like support-verb construction.

By using a corpus of bilingual Basque-Spanish conversations recorded in the Greater Bilbao area, Lantto documents an effect of codeswitching on word-order convergence. In her contribution, she conducts a contrastive analysis of usage patterns of predicative constructions in monolingual Basque and bilingual Basque-Spanish speech as represented in her corpus. 
The analysis reveals that most predicative constructions in Basque monolingual sentences follow the canonical Basque sxv order, whereas the typical order in these constructions in bilingual Basque-Spanish sentence is SVX, as in Spanish. Crucially, the predicative constructions differ from each other on the formal side, but they are equivalent functionally. In her analysis, Lantto focuses on Spanish insertions as nominal parts in otherwise Basque compound predicatives. The author concludes that the Spanish lexical items are strongly associated with the Spanish construction and thus trigger its word order pattern in bilingual sentences. Furthermore, the bilingual sentences provide evidence for an increase in overall similarity between the syntactic contexts in which Spanish words are used. This account is consistent with a usage-based view of language organization and linguistic behavior, according to which in speech production, language users draw on specific, partially specific and abstract representations. The author interprets the results in the framework of usage-based contact linguistics by identifying specific cognitive and sociolinguistic factors pertinent to the reported variation.

The article by Estigarribia looks at Guarani-origin pragmatic markers in the Spanish spoken in Paraguay, i.e., in a form of Spanish that is the result of long-term bilingualism. Unlike in many other locations in the post-colonial Spanish-speaking world, bilingualism has persisted into the present day, and one effect of this may be the incorporation of Guarani material into local Spanish, as well as the existence of separate varieties between the monolingual poles of Guarani and Spanish that differ in their degrees of admixture. The analyzed pragmatic markers attach to Spanish verbs and preserve their Guarani functions, marking such categories as emphasis, uncertainty, etc. Estigarribia argues that this incorporation of Guarani functional morphemes is the result of conceptual transfer from Guarani. As speakers plan their utterances they follow Guarani templates, as these are easily activated in their bilingual minds. The actual Guarani markers are then co-activated to fulfill functions for which there are no readily available equivalents in Spanish that are perceived as close enough. Contrary to many other postcolonial settings, the continued use of Guarani allows for the Guarani morphemes to maintain sufficient representational strength in speakers' minds to make them cognitively available during speech production. In addition, and again contrary to many other postcolonial settings, any sociolinguistic constraints that exist on importing Guarani morphemes into the local Spanish are overridden by other considerations in many contexts. In many other cases of shift-induced interference, morphemes from the host language with relatively similar functions tend to be reanalyzed to fulfill the functions or meanings imported from the other language through conceptual transfer. 


\section{References}

Abbot-Smith, Kirsten, and Michael Tomasello. 2006. Exemplar-learning and schematization in a usage-based account of syntactic acquisition. The Linguistic Review 23(3): 275-9o.

Arnon, Inbal, and Eve V. Clark. 2011. Why brush your teeth is better than teeth children's word production is facilitated in familiar sentence-frames. Language Learning and Development 7(2): 107-29.

Arnon, Inbal, and Neal Snider. 2010. More than words: Frequency effects for multiword phrases. Journal of Memory and Language 62(1): 67-82.

Backus, Ad. 1996. Two in One: Bilingual Speech of Turkish Immigrants in the Netherlands. Tilburg, Netherlands: Tilburg University Press.

Backus, Ad. 2001. The role of semantic specificity in insertional codeswitching: Evidence from Dutch-Turkish. In Jacobson, Rodolfo (ed.), Codeswitching Worldwide II, 125-154. Berlin, New York: Mouton de Gruyter.

Backus, Ad. 2003. Units in code switching: Evidence for multimorphemic elements in the lexicon. Linguistics 41(1): 83-132.

Backus, Ad. 2014. A usage-based approach to borrowability. In Zenner, Eline, and Gitte Kristiansen (eds.), New Perspectives on Lexical Borrowing: Onomasiological, methodological and phraseological innovations, 19-39. Berlin, Boston: de Gruyter.

Backus, Ad. 2015. A usage-based approach to code-switching: The need for reconciling structure and function. In Stell, Gerald, and Kofi Yakpo (eds.), Code-switching between Structural and Sociolinguistic Perspectives, 19-38. Berlin, Boston: de Gruyter.

Backus, Ad. 2020. Usage-based approaches. In Adamou, Evangelia, and Yaron Matras (eds.), The Routledge Handbook of Language Contact, 110-126. Milton Park, Abingdon, England, New York: Routledge.

Bannard, Colin, and Danielle Matthews. 2008. Stored word sequences in language learning: The effect of familiarity on children's repetition of four-word combinations. Psychological Science 19(3): 241-248.

Blumenthal-Dramé, Alice. 2012. Entrenchment in Usage-Based Theories: What Corpus Data Do and Do Not Reveal about the Mind. Berlin, Boston: de Gruyter.

Boas, Hans C. 2003. A Constructional Approach to Resultatives. Stanford, CA: CSLI Publications.

Bod, Rens. 2006. Exemplar-based syntax: How to get productivity from examples. The Linguistic Review 23(3): 291-320.

Booij, Geert. 2010. Construction Morphology. Oxford, New York: Oxford University Press.

Boumans, Louis. 1998. The Syntax of Codeswitching: Analysing Moroccan Arabic/Dutch Conversation. Tilburg: Tilburg University Press. 
Bybee, Joan L. 1985. Morphology: A Study of the Relation between Meaning and Form. Amsterdam, Philadelphia, PA: Benjamins.

Bybee, Joan L. 2001. Phonology and Language Use. Cambridge: Cambridge University Press.

Bybee, Joan L. 2002. Sequentiality as the basis of constituent structure. In Givón, Talmy, and Bertram F Malle (eds.), The Evolution of Language out of Pre-Language, 107-132. Amsterdam, Philadelphia, PA: Benjamins.

Bybee, Joan L. 2006. From usage to grammar: The mind's response to repetition. Language 82(4): 711-733.

Bybee, Joan L. 2007. Frequency of Use and the Organization of Language. Oxford, New York: Oxford University Press.

Bybee, Joan L. 2010. Language, Usage and Cognition. Cambridge, England, New York: Cambridge University Press.

Bybee, Joan L. 2013. Usage-based theory and exemplar representations. In Hoffmann, Thomas, and Graeme Trousdale (eds.), The Oxford Handbook of Construction Grammar, 49-69. Oxford, New York: Oxford University Press.

Bybee, Joan L., and Joanne Scheibman. 1999. The effect of usage on degrees of constituency: The reduction of don't in American English. Linguistics 37(4): 575-96.

Croft, William. 200o. Explaining Language Change: An Evolutionary Approach. Longman Linguistics Library. Harlow, England, New York: Longman.

Croft, William. 2001. Radical Construction Grammar: Syntactic Theory in Typological Perspective. Oxford, England, New York: Oxford University Press.

Croft, William, and D. Alan Cruse. 2004. Cognitive Linguistics. Cambridge, England, New York: Cambridge University Press.

Dąbrowska, Ewa. 1997. The LAD goes to school: A cautionary tale for nativists. Linguistics 35(4): 735-766.

Dąbrowska, Ewa. 2004. Rules or schemas? Evidence from Polish. Language and Cognitive Processes 19(2): 225-271.

Dąbrowska, Ewa. 2008. The later development of an early-emerging system: The curious case of the Polish genitive. Linguistics 46(3): 629-65o.

Dąbrowska, Ewa. 2014. Recycling utterances: A speaker's guide to sentence processing. Cognitive Linguistics 25: 617-653.

Dąbrowska, Ewa, and Elena Lieven. 2005. Towards a lexically specific grammar of children's question constructions. Cognitive Linguistics 16(3): 437-474.

Diessel, Holger. 2016. Frequency and lexical specificity. A critical review. In Behrens, Heike, and Stefan Pfänder (eds.), Experience Counts: Frequency Effects in Language, 209-237. Berlin, Boston: de Gruyter.

Diessel, Holger. 2017. Usage-based linguistics. In Aronoff, Mark (ed.), Oxford Research Encyclopedia of Linguistics. New York: Oxford University Press. 
Divjak, Dagmar, and Catherine L. Caldwell-Harris. 2015. Frequency and entrenchment. In Dąbrowska, Ewa, and Dagmar Divjak (eds.), Handbook of Cognitive Linguistics, 53-75. Berlin, Boston: de Gruyter.

Drager, Katie, and M. Joelle Kirtley. 2016. Awareness, salience, and stereotypes in exemplar-based models of speech production and perception. In Babel, Anna, (ed.), Awareness and Control in Sociolinguistic Research, 1-24. Cambridge, England, New York: Cambridge University Press.

Fillmore, Charles J. 1976. Frame semantics and the nature of language. Annals of the New York Academy of Sciences 280: 20-32.

Five Graces Group, Clay Beckner, Richard Blythe, Joan Bybee, Morten H. Christiansen, William Croft, Nick C. Ellis, et al. 20o9. Language is a complex adaptive system: Position Paper. Language Learning 59(1): 1-26.

Forker, Diana. 2020. The late success of Soviet language policy: The integration of Russian verbs in languages of the former Soviet Union. International Journal of Bilingualism. https://doi.org/10.1177/13670o6920947168.

Goldberg, Adele E. 1995. Constructions: A Construction Grammar Approach to Argument Structure. Chicago: University of Chicago Press.

Goldberg, Adele E. 20o6. Constructions at Work: The Nature of Generalization in Language. Oxford, New York: Oxford University Press.

Goldberg, Adele E., Devin M. Casenhiser, and Nitya Sethuraman. 2004. Learning argument structure generalizations. Cognitive Linguistics 15(3): 289-316.

Hakimov, Nikolay. 2016a. Explaining variation in plural marking of German noun insertions in Russian sentences. In Behrens, Heike, and Stefan Pfänder (eds.), Experience counts: Frequency effects in language, 21-6o. Berlin, Boston: de Gruyter.

Hakimov, Nikolay. 2016b. Effects of frequency and word repetition on switch-placement: Evidence from Russian-German code-mixing. In Robinson, Justyna A., and Monika Reif (eds.), Culture and Cognition in Bilingualism, 91-125. Berlin, Boston: de Gruyter. Hakimov, Nikolay. 2018 (2017). Ein gebrauchsbasierter Ansatz zur Analyse von CodeMixing. Zeitschrift für Dialektologie und Linguistik 84(2-3): 308-335.

Hakimov, Nikolay. To appear. Explaining Russian-German code-mixing: A usage-based approach to code-mixing. Berlin: Language Science Press.

Haugen, Einar. 1950. The analysis of linguistic borrowing. Language 26: 210-231.

Heine, Bernd, Ulrike Claudi, and Friederike Hünnemeyer. 1991. Grammaticalization: A Conceptual Framework. Chicago: University of Chicago Press.

Höder, Steffen. 2012. Multilingual constructions: A diasystematic approach to common structures. In Braunmüller, Kurt, and Christoph Gabriel (eds.), Hamburg Studies on Multilingualism 13, 241-258. Amsterdam: Benjamins.

Johnson, Keith. 1997. Speech perception without speaker normalization: An exemplar model. In Johnson, Keith, and John W. Mullennix (eds.), Talker Variability in Speech Processing, 145-166. San Diego: Academic Press. 
Kruszewski, Mikołaj. 1995. Writings in General Linguistics: On Sound Alternation (1881) and Outline of Linguistic Science (1883). Edited by E. F. Konrad Koerner . Amsterdam, Philadelphia, PA: Benjamins.

Lakoff, George, and Mark Johnson. 1980. Metaphors We Live by. Chicago: University of Chicago Press.

Langacker, Ronald W.1987. Foundations of Cognitive Grammar: Theoretical Prerequisites. Vol. 1. Stanford, CA: Stanford University Press.

Langacker, Ronald W. 1991. Foundations of Cognitive Grammar: Descriptive Application. Vol. 2. Stanford, CA: Stanford University Press.

Langacker, Ronald W. 2008. Cognitive Grammar: A Basic Introduction. Oxford, New York: Oxford University Press.

Lieven, Elena. 2010. Input and first language acquisition: Evaluating the role of frequency. Lingua 120(11): 2546-2556.

Lieven, Elena V. M., Julian M. Pine, and Gillian Baldwin. 1997. Lexically-based learning and early grammatical development. Journal of Child Language 24(1):187-219.

Lieven, Elena, Dorothé Salomo, and Michael Tomasello. 20o9. Two-year-old children's production of multiword utterances: A usage-based analysis. Cognitive Linguistics $20(3): 481-507$.

MacWhinney, Brian, and William O'Grady (eds.). 2015. The Handbook of Language Emergence. Hoboken: Wiley-Blackwell.

Matras, Yaron. 2013. Contact, convergence, and typology. In Hickey, Raymond (ed.), The Handbook of Language Contact, 66-85. Oxford, UK: Wiley-Blackwell.

Medin, Douglas L. and Marguerite M. Schaffer. 1978. Context theory of classification learning. Psychological Review 85: 207-238.

Muysken, Pieter. 1981. Halfway between Quechua and Spanish: The case for relexification. In Highfield, Arnold, and Albert Valdman (eds.), Historicity and Variation in Creole Studies, $5^{2-78}$. Ann Arbor: Karoma.

Muysken, Pieter. 200o. Bilingual Speech: A Typology of Code-Mixing. Cambridge, England, New York: Cambridge University Press.

Myers-Scotton, Carol. 1993. Duelling Languages: Grammatical Structure in Codeswitching. Oxford, England, New York: Clarendon Press, Oxford University Press.

Myers-Scotton, Carol, and Janice L. Jake. 1995. Matching lemmas in a bilingual language competence and production model: Evidence from intrasentential code-switching. Linguistics 33: 981-1024.

Nosofsky, Robert M. 1988. Similarity, frequency, and category representations. Journal of Experimental Psychology: Learning, Memory, and Cognition 14(1): 54-65.

Nosofsky, Robert M. 2011. The generalized context model: An exemplar model of classification. In Pothos, Emmanuel M., and Andy J. Wills (eds.), Formal Approaches in Categorization, 18-39. Cambridge, England, New York: Cambridge University Press. 
Pfänder, Stefan, and Anna Babel. 2014. Doing copying: Why typology doesn't matter to language speakers. In Besters-Dilger, Juliane, Cynthia Dermarkar, Stefan Pfänder, and Achim Rabus (eds.), Congruence in Contact-Induced Language Change, Language Families, Typological Resemblance, and Perceived Similarity, 239-257. Berlin, Boston: de Gruyter.

Pierrehumbert, Janet. 2001. Exemplar dynamics: Word frequency, lenition and contrast. In Bybee, Joan L., and Paul J. Hopper (eds.), Frequency and the Emergence of Linguistic Structure, 137-157. Amsterdam, Philadelphia, PA: Benjamins.

Pierrehumbert, Janet. 2002. Word-specific phonetics. In Gussenhoven, Carlos, and Natasha Warner (eds.), Laboratory Phonology 7, 101-39. Berlin, Boston: de Gruyter Mouton.

Poplack, Shana. 1980. Sometimes I'll start a sentence in Spanish y termino en español: Toward a typology of code-switching. Linguistics 18(7-8): 581-618.

Poplack, Shana, David Sankoff, and Christopher Miller. 1988. The social correlates and linguistic processes of lexical borrowing and assimilation. Linguistics 26(1): 47-104.

Poplack, Shana, and Nathalie Dion. 2012. Myths and facts about loanword development. Language Variation and Change 24(3): 279-315.

Sankoff, David, Shana Poplack, and Swathi Vanniarajan. 199o. The case of the nonce loan in Tamil. Language Variation and Change 2(1): 71-101.

Schmid, Hans-Jörg (ed.). 2017. Entrenchment and the Psychology of Language Learning: How We Reorganize and Adapt Linguistic Knowledge. Berlin, Boston: de Gruyter.

Sebba, Mark. 20o9. On the notions of congruence and convergence in code-switching. In Bullock, Barbara E., and Almeida Jacqueline Toribio (eds.), The Cambridge Handbook of Linguistic Code-Switching, 40-57. Cambridge, England, New York: Cambridge University Press.

Speed, Laura J., David P. Vinson, and Gabriella Vigliocco. 2015. Representing meaning. In Dąbrowska, Ewa, and Dagmar Divjak (eds.), Handbook of Cognitive Linguistics, 19o-211. Berlin, Boston: de Gruyter.

Talmy, Leonard. 1977. Rubber sheet cognition in language. In Beach, Woodford A., Samuel E. Fox, and Shulamith Philosoph (eds.), Papers from the Thirteenth Regional Meeting, Chicago Linguistic Society, 612-628. Chicago: Chicago Linguistic Society.

Talmy, Leonard. 2000. Toward a Cognitive Semantics. Language, Speech, and Communication. Cambridge, MA: MIT Press.

Tomasello, Michael. 1992. First Verbs: A Case Study of Early Grammatical Development. Cambridge, England, New York: Cambridge University Press.

Tomasello, Michael. 2003. Constructing a Language: A Usage-Based Theory of Language Acquisition. Cambridge, MA; London, UK: Harvard University Press.

Traugott, Elizabeth Closs, and Graeme Trousdale. 2013. Constructionalization and Constructional Changes. Oxford: Oxford University Press. 
Treffers-Daller, Jeanine. 1994. Mixing Two Languages: French-Dutch Contact in a Comparative Perspective. Berlin, New York: Mouton de Gruyter.

Verschik, Anna. 2019. English-Estonian code-copying in blogs: Combining contact linguistic and cognitive approach. In Zenner, Eline, Ad Backus, and Esme WinterFroemel (eds.), Cognitive Contact Linguistics, 51-80. Berlin, Boston: de Gruyter.

Vihman, Marilyn, and William Croft. 2007. Phonological development: Toward a 'radical' templatic phonology. Linguistics 45(4): 683-725.

Weinreich, Uriel. 1979 [1953]. Languages in Contact: Findings and Problems. 9th ed. The Hague; Paris; NY: Mouton. 